\title{
The primary stability of different implants for intra-articular calcaneal fractures: an in vitro study
}

\author{
Ming $\mathrm{Ni}^{1}{ }^{, 2}$, Jiong $\mathrm{Mei}^{3}$, Kun $\mathrm{Li}^{1}$, Wenxin $\mathrm{Niu}^{2^{*}}$ (1) and Ming Zhang ${ }^{4}$
}

*Correspondence:
niu@tongji.edu.cn
2 Shanghai Yangzhi
Rehabilitation Hospital,
Tongji University
School of Medicine, No.
2209, Guangxing Rd,
Shanghai 201619, China
Full list of author information
is available at the end of the
article

(c) The Author(s) 2018. This article is distributed under the terms of the Creative Commons Attribution 4.0 International License (http://creativecommons.org/licenses/by/4.0/), which permits unrestricted use, distribution, and reproduction in any medium, provided you give appropriate credit to the original author(s) and the source, provide a link to the Creative Commons license, and indicate if changes were made. The Creative Commons Public Domain Dedication waiver (http://creativecommons.org/publi cdomain/zero/1.0/) applies to the data made available in this article, unless otherwise stated.
Conclusions: The global stiffness was similar when the calcaneal fractures were fixed by K-wires, CS and PSS. The stability of the AS fixation differed along both the vertical and anterior-posterior directions, and was greatly influenced by the bone quality. AS for fracture fixation should be designed with greater strength and pull-out resistance.

Keywords: Calcaneal fractures, Absorbable screw, Fracture fixation, Internal fixation, In-vitro experiment 


\section{Background}

Calcaneal fractures account for around $2 \%$ of all fractures presented to emergency departments and approximately $75 \%$ of these are intra-articular fractures involving the posterior subtalar joint [1]. Treatments for displaced intra-articular calcaneal fractures can be divided into conservative and operative management [2-4]. A review of treatment options showed that patients may have superior outcomes with surgical fixation [5].

The goals of surgical treatment of calcaneal fractures are to reduce fractures and articular congruity, provide stable fixation, and regain motion early in the postoperative period. A number of implants, like the Kirschner wires (K-wires), absorbable screws (AS), cannulated screws (CS), and plate-screw system (PSS), have been successfully used for the internal fixation of calcaneal fractures [6-9]. The stability of the fixation is an important factor in maintaining the position of the reduction, but previous biomechanical studies were mostly concerned about plate selection and implant type [10-14]. The biomechanical stability of different devices has not yet been well investigated and there is no clear evidence which one will produce the best stability for calcaneal fractures. In previous studies, vertical stiffness was the only parameter considered when gauging the biomechanical stability of internal fixation. Obviously, more indexes should be considered when evaluating such multi-axial movements.

The purpose of this study is to compare the biomechanical stability of intra-articular calcaneal fractures after fixation with four common implants: K-wires, AS, CS, and PSS. Fixation was tested in both vertical and horizontal directions. Because of the insufficient stiffness of absorbable material, the null hypothesis was that fixation with K-wires, CS and PSS would be biomechanically superior to fixation with AS.

\section{Methods}

\section{Preparation of cadaveric specimens}

Eight calcaneus specimens were harvested from fresh cadavers. Four right feet and four left feet were used. The donors had a mean age at death of 50.5 (38-72) years and the mean foot length was $24.4(23.8-25.6) \mathrm{cm}$. Radiographs were taken of each specimen to rule out bone abnormalities and previous injuries. The specimens were present and stored at $-20{ }^{\circ} \mathrm{C}$ and thawed at room temperature for $24 \mathrm{~h}$ before testing. The calcanei were cleaned of all soft tissues before simulation and fixation.

\section{Fracture model and fixation}

The Sanders' type III calcaneal fractures were simulated as described by Smerek et al. [15]. Firstly, a V-shaped osteotomy was made near the angle of Gissane in the coronal plane which divided the calcaneus into three fragments. The central fragment contained most of the posterior facet. Next, two sagittal osteotomies were made on the central fragment which divided it into three parts: the sustentaculum, and the middle and internal posterior facet.

After the osteotomy, the fractures were fixed using four different implants: K-wires, CS, AS, and PSS. The smooth K-wires (Puwei Ltd., Shanghai, China) had a diameter of 2-mm. The CS (Puwei Ltd., Shanghai, China) were titanium, short-threaded screws, with 


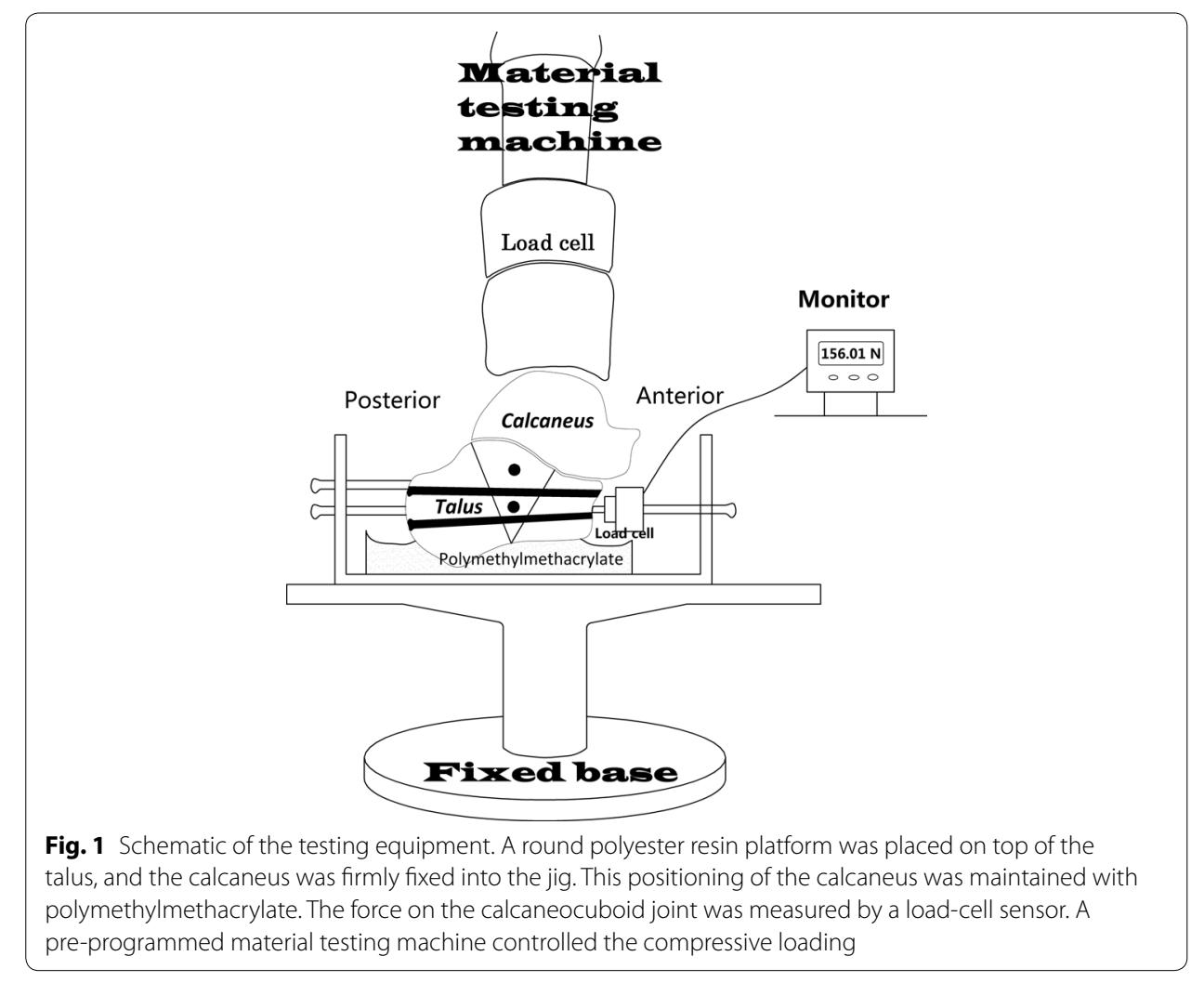

diameters of 4.0- and 7.3-mm. The AS (Dikang Biomedical Co., Ltd., Chengdu, China) were made from Poly-L-lactide acid (PLLA) and had diameters of 4.0- and 7.3- $\mathrm{mm}$. The PSS (Puwei Ltd., Shanghai, China) was a non-locking stainless steel AO "Sanders plate" with cancellous screws.

The K-wires and screws were inserted in a cross configuration. Two wires were inserted from the lateral side beneath the posterior facet to the sustentaculum tali and two from calcaneal tuberosity in the direction of the calcaneocuboid joint but not penetrated into joint. The plate was fixed using three screws beneath the posterior facet, three in the posterior process and two in the anterior process. All screws were inserted in a bicortical manner. The middle screw under the posterior facet was directed to reach the sustentaculum in all cases.

\section{Biomechanical tests}

For mechanical testing, the posteroinferior calcaneal tuberosity was potted in a holder using polymethylmethacrylate (Technovit 3040; Heraeus Kulzer GmbH, Wehrheim, Germany). The calcaneus was inclined at $15^{\circ}$ and the hindfoot was maintained at $90^{\circ}$ to the horizontal plane of the holder to simulate the anatomical position of the heel. Each specimen was then placed into a custom-made jig. The calcaneus was firmly fixed with two metal boards and six locked screws. The anterior board could move in the mediolateral direction and posterior in the anterior-posterior (AP) direction to obtain the appropriate positioning of the calcaneus. As shown in Fig. 1, the calcaneocuboid force 
was measured by a load-cell sensor (Xinjingcheng, Shenzhen, China) with the range of 0-1000 N. The sensor was placed in the center of the joint and was bolted to the jig.

All tests were performed on a material testing machine (CSS-44000; CRIMS Co., Ltd., Changchun, China). The load was applied and transmitted through the talus which was placed on the upper surface of the calcaneus (Fig. 1). Each specimen was tested under five operating conditions in the following order: (1) intact calcaneus; (2) calcaneal fracture fixed by K-wires; (3) fracture fixed by CS; (4) fracture fixed by AS; and (5) fracture fixed by PSS. When one fixation model was tested, the implants were removed. This order was based on the morphological features and size of four fixation implants in order to avoid the influence of earlier operations. The CS were used prior to AS because some bones could be remained along the hollow threaded rod.

\section{Data acquisition}

The specimens were preconditioned by axial loading $(0-200 \mathrm{~N})$ through five cycles at the rate of $2 \mathrm{~mm} / \mathrm{min}$ before formal testing of each model. Specimens were then subjected to axial stepwise loading. The load-displacement curve of calcaneus was continuously recorded by a transducer. When the load through the material testing machine increased, the calcaneocuboid force would also increase and its value could be read through a monitor (Fig. 1). The maximum value was regcorded as the peak force of calcaneocuboid joint. The calcaneocuboid peak pressure has been found to successfully assess stability of normal foot, flat foot and corrected flatfoot deformity [16]. Because the contact force through this joint represents the AP mechanical effect, it should be used as an index of the stability in this direction. The reproducibility of the loading procedure was tested by sequentially loading the same specimen three consecutive times while maintaining all other parameters constant. The average value of three tests was used for further statistical analysis. Then, each calcaneus bone was tested 15 times.

\section{Statistical analysis}

Statistical analysis was performed using Statistical Package for Social Sciences (SPSS) for Windows, Version 18.0.1 (SPSS Inc., Chicago, IL, USA). One-way analysis of variance (ANOVA) was used for data analysis. When significant differences occurred during the ANOVA test, a post hoc multiple was used to locate the differences between the different specimens. The null hypothesis at the level $p<0.05$ was that there were differences between the different implants.

\section{Results}

None of calcaneal fracture fixations tested failed during the vertical loading. The loaddisplacement curves of a representative sample were shown as Fig. 2. A comparison of vertical stiffness among different models is shown in Fig. 3. The intact model showed the highest stiffness of 634 (383-891; SD 226) N/mm. It was significantly higher than the models fixed with K-wires, CS or PSS, with the $p$ value of $0.007,0.032$, and 0.008 respectively. There was no significant difference in vertical stiffness between fractures fixed with AS and the intact model or other fixed models. 


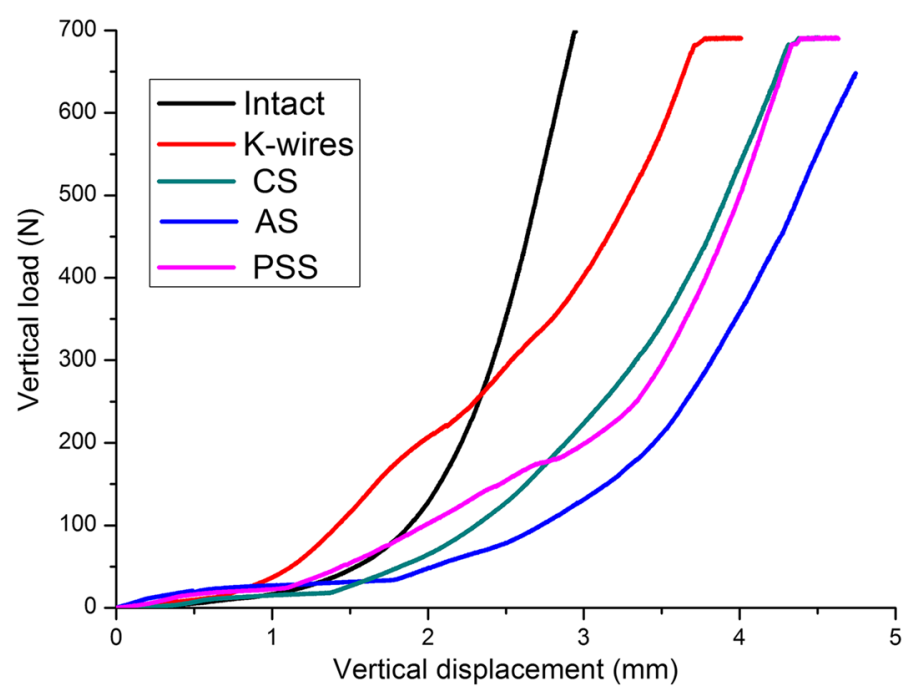

Fig. 2 The load-displacement curves of intact and four fixation models for a representative sample. CS cannulated screws, AS absorbable screws, PSS plate-screw system

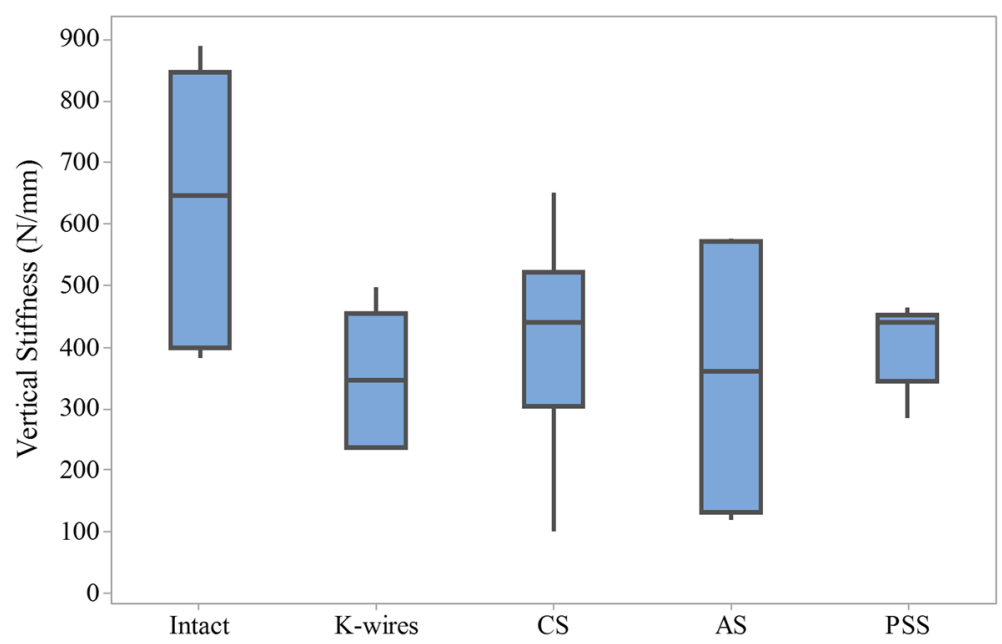

Fig. 3 Box and whisker plots for the vertical stiffness of five conditions. The box indicates the interquartile range. CS cannulated screws, AS absorbable screws, PSS plate-screw system

Anterior-posterior stability was measured by the calcaneocuboid force. A comparison of the AP stability among all models is shown in Fig. 4. The intact model showed the lowest force of 153 (120-218; SD 39) N, while the fractures fixed with AS showed the greatest force of 242 (146-398; SD 84) N. The significance was only detected between these two models ( $\mathrm{p}$ value 0.02 ). 


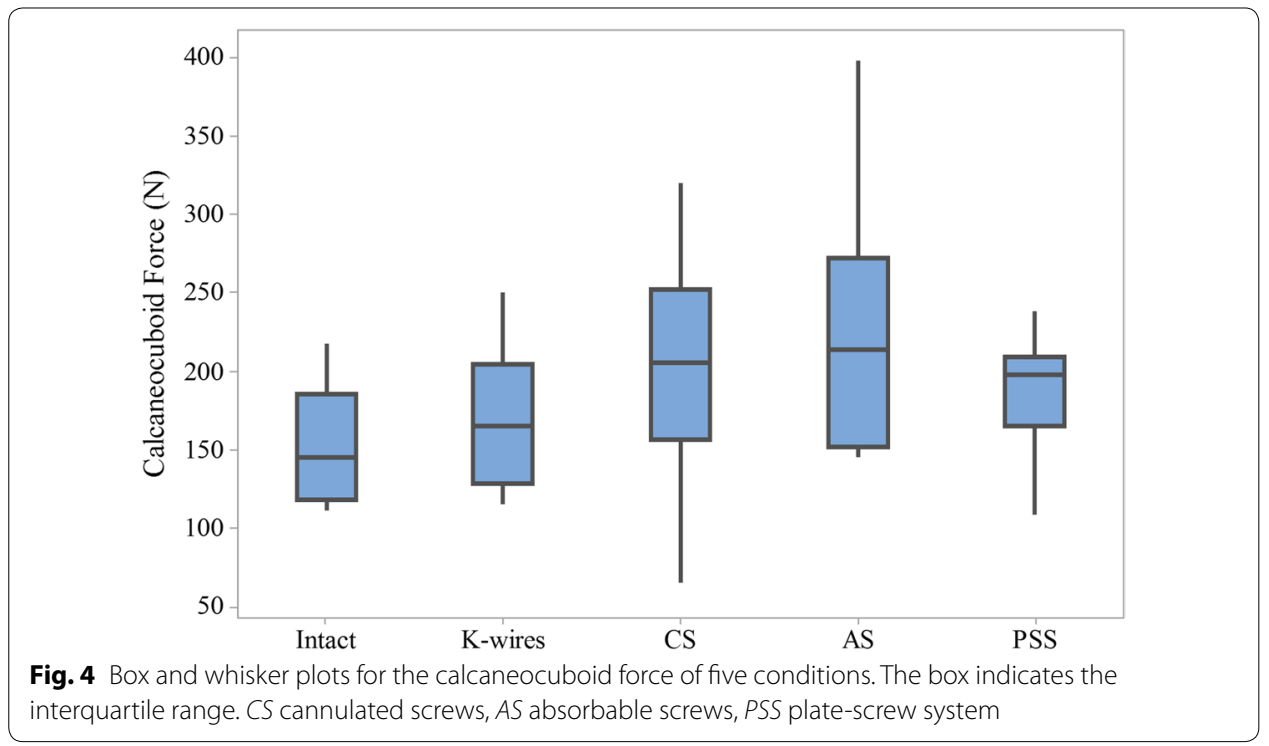

\section{Discussion}

A variety of techniques have been proposed for the fixation of calcaneal fractures, but the optimal fixation technique has not yet been devised, partly due to a lack of biomechanical evidence. Few reports have been published on the biomechanical performance of different implants for the fixation of intra-articular calcaneal fractures. The results presented here are of value not only for future research, but serve as an objective measure for surgeons to justify the choice of one implant over another.

Percutaneous screws fixation has been shown to disrupt less soft tissue than plating, but provide favorable clinical outcomes [6, 17-19]. There are a variety of accepted approaches for placing screws within the fractured calcaneus, but it remains unclear which configuration provides greater biomechanical strength and stiffness. It has been suggested that screws inserted perpendicular to the fracture plane could provide superior inter-fragmental fixation [14]. In our study, four cruciate screws were inserted perpendicularly to the fracture plane to attain a more stable fixation.

K-wires are commonly used for temporary intra-operative fixation, to aid in intraoperative exposure or as definitive fixation in specific patient populations. K-wires have successfully been used for the fixation of calcaneal fractures $[9,20]$. Pelliccioni et al. [21] made a systematic review on the surgical treatment of intra-articular Sanders' type II and III calcaneal fractures and found percutaneous fixation using K-wires presented the best results. However, the clinical evidence is insufficient to assert the biomechanical superiority of this treatment in comparison with other surgical techniques.

The stance phase of gait was simulated in this study to compare the stability of four implants for securing a Sander's type III calcaneal fracture. The results showed that none of the samples failed during loading up to $700 \mathrm{~N}$. This indicated that all four internal constructs potentially allow active ankle mobilization and early rehabilitation after operation without re-displacement of the fractures. 
There was no significant difference in vertical stability among the models fixed with K-wires, CS or PSS, but they were weaker than the intact calcaneus. This suggested that calcaneal fractures after fixation should avoid weight bearing activities during the early post-operative stages. However, the stiffness of fractures fixed by AS was similar to that of the intact model. One possible explanation is that the calcaneal models used this study were with varying levels of bone quality. Absorbable implants are stiffer than cancellous bone $[22,23]$, and any bone displacements in the calcaneal models depend on the bone quality. Under the same load, the calcaneal models with good bone quality moved less than those of osteoporosis, which made the overall results comparable with the intact calcaneus. This suggested that when surgeons choose AS for calcaneal fractures, they should consider not only the fracture types but the bone quality.

Under axial compressive loading, the calcaneal fragments could move along both vertical and AP directions [24]. The AP displacement or the force at the calcaneocuboid joint could be used as an index for the assessment of stability. In previous studies, the AP stability of the calcaneus has less been mentioned. In this study, the calcaneocuboid force was measured and showed a satisfactory correlation with the vertical stability on both intact and fracture models. The intact calcaneus showed superior stability than fracture models with regard to higher stiffness and lower calcaneocuboid force. This was consistent with some biomechanical studies which compare the stability of intact and repaired bone models $[25,26]$. In addition, the biomechanical stability of K-wires, CS and PSS was similar in both vertical and AP direction.

The fixation with AS was significantly less stable than the intact model. This can be explained by the weak stiffness of the AS and the small thread depth. To gain enough strength, AS are typically designed with a large diameter and small thread depth. Therefore, AS with greater strength and pull-out resistance should be encouraged to satisfy clinical needs.

Although the K-wires, CS and PSS showed similar stability in both vertical and AP stability, it should be noted that the calcaneal fractures tested were simulated fractures and without bone defects. In the clinical setting, the size and number of intra-articular fragments vary greatly among patients, and the longitudinal fracture lines of the calcaneus are sometimes much longer than in the current models. For comminuted calcaneal fractures or those with osteoporosis, PSS fixation would be the first recommendation for its framed structure and multi-point fixation. With regards to K-wires or CS, calcaneal fractures with two or three segments were the main indications and the patients deemed unsuitable for open operative treatment. The use of AS was determined by both fracture type and bone quality.

There were also some limitations to this study. Firstly, the cadaver samples used showed a large variation in bone quality, because cadaveric specimens utilized in the study were with a great range of death age. Although the use of synthetic bone could avoid the problem of osteoporosis, we believe that cadaveric calcaneus better represented the in vivo state, including compression of the subtalar joint and movement of calcaneocuboid joint. Secondly, the same calcaneus model was consecutively tested under intact and fracture conditions due to the limitation of specimen numbers. However, this procedure was common in biomechanical studies [16, 25, 27], and the simulated physiological 
loading would not bring much damage to calcaneus structures. Thirdly, the surrounding soft tissues were not considered in this study because the musculature was not active in the cadaveric samples. Soft tissues such as muscles, tendons and ligaments do provide additional support for the skeletal system. This might have an influence on experimental results and should be taken into account in future studies.

\section{Conclusions}

This biomechanical study investigated the fixation strength of four different implants for treating Sanders' types III calcaneal fractures. The global stiffness was similar when the calcaneal fractures were fixed by K-wires, CS and PSS. The stability of the fixation with AS differed along the vertical and AP directions, and was greatly influenced by the bone quality. AS for fracture fixation should be designed with greater strength and pull-out resistance.

\section{Abbreviations}

ANOVA: analysis of variance; AP: anterior-posterior; AS: absorbable screws; CS: cannulated screws; K-wire: Kirschner wire; PLLA: poly-L-lactide acid; PSS: plate-screw system.

\section{Authors' contributions}

MN conceived, designed and performed the experiment, analyzed the data and wrote the paper; JM and WN conceived and designed the experiment and reviewed the paper; KL and MZ reviewed the analysis and the paper. All authors read and approved the final manuscript.

\section{Author details}

${ }^{1}$ Department of Orthopedics, Pudong New Area People's Hospital, Shanghai, China. ${ }^{2}$ Shanghai Yangzhi Rehabilitation Hospital, Tongji University School of Medicine, No. 2209, Guangxing Rd, Shanghai 201619, China. ${ }^{3}$ Department of Orthopedics, Tongji Hospital, Tongji University School of Medicine, Shanghai, China. ${ }^{4}$ Department of Biomedical Engineering, The Hong Kong Polytechnic University, Hong Kong, China.

Acknowledgements

We thank Dr. Colin McClean for language editing.

Competing interests

The authors declare that they have no competing interests.

Availability of data and materials

The datasets used and/or analyzed during the current study available from the corresponding author on reasonable request.

Ethics approval and consent to participate

An ethical approval was given by the Medicine and Life Sciences Ethics Committee of Tongji University (No. 2014yxy21).

Funding

This work was supported by National Natural Science Foundation of China (11732015).

\section{Publisher's Note}

Springer Nature remains neutral with regard to jurisdictional claims in published maps and institutional affiliations.

Received: 27 May 2017 Accepted: 23 April 2018

Published online: 02 May 2018

\section{References}

1. Schepers T, van Lieshout EMM, van Ginhoven TM, Heetveld MJ, Patka P. Current concepts in the treatment of intraarticular calcaneal fractures: results of a nationwide survey. Int Orthop. 2008:32:711-5.

2. Agren PH, Wretenberg P, Sayed-Noor AS. Operative versus nonoperative treatment of displaced intra-articular calcaneal fractures. J Bone Joint Surg Am. 2013;95:1351-7.

3. Guerado E, Bertrand ML, Cano JR. Management of calcaneal fractures: what have we learnt over the years? Injury. 2012;43:1640-50.

4. Veltman ES, Doornberg JN, Stufkens SA, Luitse JS, van den Bekerom MP. Long-term outcomes of 1,730 calcaneal fractures: systematic review of the literature. J Foot Ankle Surg. 2013;52:486-90. 
5. Gougoulias N, Khanna A, McBride DJ, Maffulli N. Management of calcaneal fractures: systematic review of randomized trials. Br Med Bull. 2009;92:153-67.

6. Hammond AW, Crist BD. Percutaneous treatment of high-risk patients with intra-articular calcaneus fractures: a case series. Injury. 2013;44:1483-5.

7. Kesemenli CC, Memisoglu K, Atmaca H. A minimally invasive technique for the reduction of calcaneal fractures using the Endobutton ${ }^{\circledR}$. J Foot Ankle Surg. 2013;52:215-20.

8. Min W, Munro M, Sanders R. Stabilization of displaced articular fragments in calcaneal fractures using bioabsorbable pin fixation: a technique guide. J Orthop Trauma. 2010;24:770-4.

9. Walde TA, Sauer B, Degreif J, Walde HJ. Closed reduction and percutaneus Kirschner wire fixation for the treatment of dislocated calcaneal fractures: surgical technique, complications, clinical and radiological results after 2-10 years. Arch Orthop Trauma Surg. 2008;128:585-91.

10. Goldzak M, Simon P, Mittlmeier T, Chaussemier M, Chiergatti R. Primary stability of an intramedullary calcaneal nail and an angular stable calcaneal plate in a biomechanical testing model of intraarticular calcaneal fracture. Injury. 2014;45:S49-53.

11. Nelson JD, MclffTE, Moodie PG, Iverson JL, Horton GA. Biomechanical stability of intramedullary technique for fixation of joint depressed calcaneus fracture. Foot Ankle Int. 2010;31:229-35.

12. Richter M, Droste P, Goesling T, Zech S, Krettek C. Polyaxially-locked plate screws increase stability of fracture fixation in an experimental model of calcaneal fracture. J Bone Joint Surg Br. 2006:88:1257-63.

13. Stoffel K, Booth G, Rohrl SM, Kuster M. A comparison of conventional versus locking plates in intraarticular calcaneus fractures: a biomechanical study in human cadavers. Clin Biomech (Bristol, Avon). 2007:22:100-5.

14. Wang CL, Chang GL, Tseng WC, Yu CY, Lin RM. Strength of internal fixation for calcaneal fractures. Clin Biomech (Bristol, Avon). 1998:13:230-3.

15. Smerek JP, Kadakia A, Belkoff SM, Knight TA, Myerson MS, Jeng CL. Percutaneous screw configuration versus perimeter plating of calcaneus fractures: a cadaver study. Foot Ankle Int. 2008;29:931-5.

16. Xia J, Zhang P, Yang YF, Zhou JQ, Li QM, Yu GR. Biomechanical analysis of the calcaneocuboid joint pressure after sequential lengthening of the lateral column. Foot Ankle Int. 2013;34:261-6.

17. Abdelgaid SM. Closed reduction and percutaneous cannulated screws fixation of displaced intra-articular calcaneus fractures. Foot Ankle Surg. 2012;18:164-79.

18. DeWall M, Henderson CE, McKinley TO, Phelps T, Dolan L, Marsh J. Percutaneous reduction and fixation of displaced intra-articular calcaneus fractures. J Orthop Trauma. 2010;24:466-72.

19. Tomesen T, Biert J, Frölke J. Treatment of displaced intra-articular calcaneal fractures with closed reduction and percutaneous screw fixation. J Bone Joint Surg Am. 2011;93:920-8.

20. Demcoe AR, Verhulsdonk M, Buckley RE. Complications when using threaded K-wire fixation for displaced intraarticular calcaneal fractures. Injury. 2009;40:1297-301.

21. Pelliccioni AA, Bittar CK, Zabeu JL. Surgical treatment of intraarticular calcaneous fractures of sanders'types II and III: systematic review. Acta Ortop Bras. 2012;20:39-42.

22. Ni M, Weng XH, Mei J, Niu WX. Primary stability of absorbable screw fixation for intra-articular calcaneal fractures: a finite element analysis. J Med Biol Eng. 2015;35:236-41.

23. Stener S, Ejerhed L, Sernert N, Laxdal G, Rostgård-Christensen L, Kartus J. A long-term, prospective, randomized study comparing biodegradable and metal interference screws in anterior cruciate ligament reconstruction surgery radiographic results and clinical outcome. Am J Sports Med. 2010;38:1598-605.

24. Giddings VL, Beaupre GS, Whalen RT, Carter DR. Calcaneal loading during walking and running. Med Sci Sports Exerc. 2000;32:627-34.

25. Cheng L, Yu Y, Zhu R, Lv H, Jia Y, et al. Structural stability of different reconstruction techniques following total sacrectomy: a biomechanical study. Clin Biomech (Bristol Avon). 2011;26:977-81.

26. Chen SH, Chiang MC, Hung CH, Lin SC, Chang HW. Finite element comparison of retrograde intramedullary nailing and locking plate fixation with/without an intramedullary allograft for distal femur fracture following total knee arthroplasty. Knee. 2014;21:224-31.

27. Ma J, Jia H, Ma X, Yu J, Feng R, et al. Evaluation of the stress distribution change at the adjacent facet joints after lumbar fusion surgery: a biomechanical study. Proc Inst Mech Eng H. 2014;228:665-73.

Ready to submit your research? Choose BMC and benefit from:

- fast, convenient online submission

- thorough peer review by experienced researchers in your field

- rapid publication on acceptance

- support for research data, including large and complex data types

- gold Open Access which fosters wider collaboration and increased citations

- maximum visibility for your research: over 100M website views per year

At BMC, research is always in progress.

Learn more biomedcentral.com/submissions 